\title{
Introduction Special section: exotic pest update
}

$W^{\text {ith its bustling international trade, }}$

$\checkmark$ moderate climate, diverse crops, and year-round tourist traffic, California is especially vulnerable to exotic pests. Exotic species which have become established here are responsible for $67 \%$ of all crop losses and are the reason for most pesticide use statewide.

This issue features several articles updating readers on the exotic pest picture in California. Articles include news stories on red imported fire ant and Africanized honey bees; research articles on weed, insect and disease pests, and a review of the CDFA Preventative Release Program to control Mediterranean fruit fly outbreaks.

Public policy on exotic pests will also be the subject of the upcoming UC Agricultural Issues Center conference May 25 in Sacramento. For more information about the conference contact the Agricultural Issues Center at (530) 752-2320 or agissues@ucdavis.edu.
-Editor

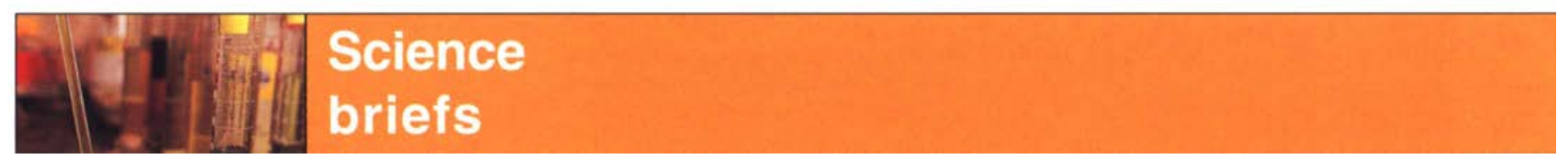

\section{AHB headed to Central Valley?}

Four dogs were killed and 14 people were injured by Africanized honey bees in 1998 in Riverside and Imperial counties and several

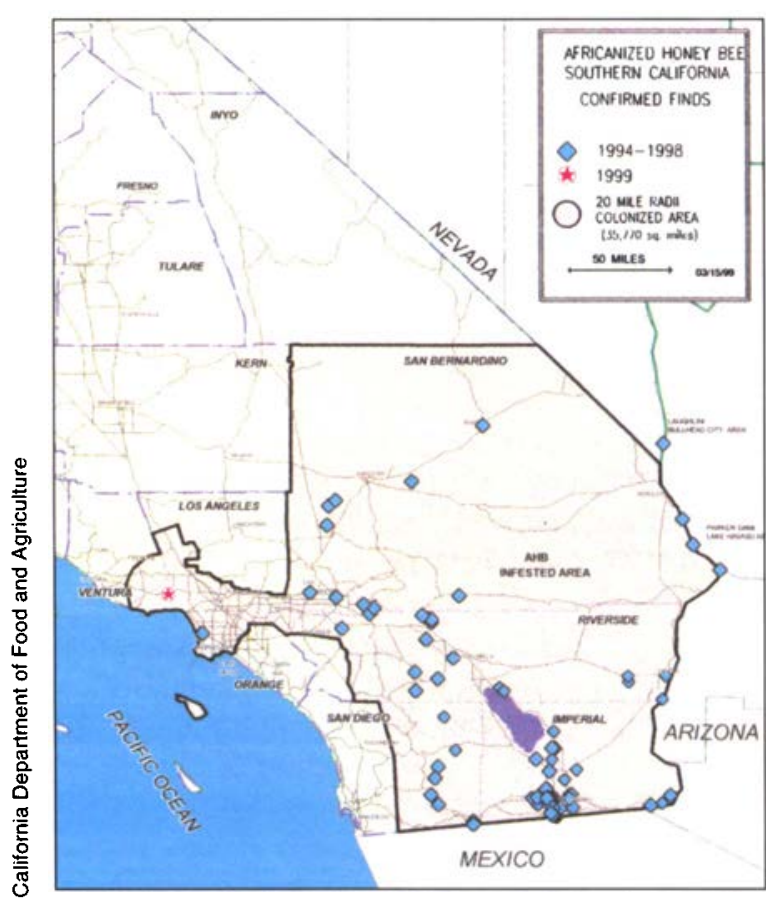

With the March 5 find of Africanized honey bees in Calabasas, the expansion of Africanized honey bees encompasses Imperial and San Bernadino counties and parts of San Diego, Los Angeles, Riverside and Ventura counties. the southeastern region of the state were Africanized. In 1997, 7\% of the bees they captured were Africanized.

The bees have not only increased in number but also greatly in range. The bees have since moved well north into the Mojave Desert with the outermost finds near Victorville, Barstow and Las Vegas. The extensive desert bloom in the spring following the wet winter of 1997 may have provided additional foraging opportunities.

During 1998, the scientists also found Africanized bees near 5,000 feet in the mountains surrounding the L.A. Basin. Advancement into the L.A. Basin shows the AHB's ability to overcome environmental barriers and exploit new habitat. Nielsen says AHB finds near Barstow in 1998 indicate it is likely that the bees have since moved toward the base of the Tehachapis - the mountain range separating the Mojave Desert from the San Joaquin Valley.

The many new AHB finds in the L.A. Basin in 1999 are evidence that the bees have successfully colonized this region. Human activities, ample food and abundant water create an ideal environment year-round for Africanized bees to greatly increase their numbers. The mild coastal conditions, available forage and lack of mountainous barriers will allow the bees to spread easily along the coastline to neighboring areas such as San Diego and Santa Barbara.

"The extent of the bees potential northern advancement is unknown," Nielsen says, "but Monterey and San Francisco are very feasible destinations. Once the coast is colonized, movement into the Central Valley from these coastal regions is extremely likely due to the low elevation of the Coast Range." 